\title{
"Verdugueo»: sentidos subjetivos acerca del hostigamiento policial que sufren jóvenes de sectores populares de Córdoba (Argentina)
}

\author{
Andrea Bonvillani \\ Universidad Nacional de Córdoba, Córdoba. Argentina \\ Email: abonvillani@gmail.com
}

\begin{abstract}
Resumen: En las últimas décadas en Argentina se ha desarrollado un campo de estudios sobre violencia policial, con énfasis en las prácticas de hostigamiento sufridas por jóvenes de sectores populares. Este artículo focaliza en el sentido subjetivo, es decir, las significaciones subjetivas y el registro emocional que estas experiencias tienen para las víctimas. En el marco de una estrategia metodológica cualitativa, se desarrollaron distintas técnicas conversacionales (entrevistas en profundidad, talleres socio-educativos, conversaciones en marcha). Verdugueo es una categoría local que los propios jóvenes utilizan para designar estas experiencias cotidianas, incluyendo uso de violencia física sobre los cuerpos y de la palabra con fines intimidatorios. Conjuga humillación y vergüenza como sentimientos predominantes y expresa el ejercicio de poder del estado policial cordobés, articulando discrecionalidad, impunidad y espectacularización.
\end{abstract}

Palabras clave: Represión policial; juventudes populares; castigos corporales; intimidación psicológica.

\section{«Verdugueo»: subjective senses about police harassment suffered by young people from low-income sectors of Córdoba (Argentina)}

\begin{abstract}
Over the past few decades, Argentina has developed a field of study on police violence, with emphasis on the harassment practices suffered by young people from low-income sectors. This article focuses on the subjective sense, that is, the subjective meanings and emotional record that these experiences have for the victims. Within the framework of a qualitative methodological strategy, different conversational techniques were developed (in-depth interviews, socio-educational workshops, ongoing conversations), which are complemented by answers to open-ended questions from a survey. Verdugueo is a local category that young people themselves use to designate these everyday experiences, including the use of physical violence on bodies and the use of speech for intimidating purposes. It combines humiliation and shame as predominant feelings and expresses the exercise of power by the Cordovan police state, articulating discretion, impunity, and spectacularization.
\end{abstract}

Keywords: Police repression; low-income youth; corporal punishments; psychological intimidation.

\section{«Verdugueo»: sentidos subjetivos sobre o assédio policial sofrido por jovens de setores populares de Córdoba (Argentina)}

Resumo: Nas últimas décadas, na Argentina, desenvolveu-se um campo de estudos sobre violência policial, com ênfase nas práticas de assédio sofridas por jovens de setores populares. Este artigo enfoca os significados subjetivos e o registro emocional que essas experiências têm para as vítimas. No âmbito de uma estratégia metodológica qualitativa, foram desenvolvidas diferentes técnicas de conversação (entrevistas em profundidade, oficinas socioeducativas, conversas em andamento). Verdugueo é uma categoria local que os próprios jovens usam para designar essas experiências diárias, incluindo o uso de violência física nos corpos e também da palavra para propósitos de intimidação. Combina humilhação e vergonha como sentimentos predominantes e expressa o exercício do poder do estado policial de Córdoba, articulando discrição, impunidade e espetacularização. 
Palavras-chave: Repressão policial; juventude popular; punição corporal; intimidação psicológica.

\section{Introducción}

En Córdoba, uno de los distritos provinciales de la República Argentina, en 2014 se documentaron 17 casos de gatillo fácil ${ }^{1}$, siendo la mayoría jóvenes entre 18 y 35 años. La letalidad del uso de la fuerza policial en dicha provincia argentina, es el punto culminante de un proceso represivo que lleva ya varios años, consistente en una amplia gama de prácticas cotidianas que exhiben distintos grados de violencia. En este gradiente, ocupan un lugar destacado las denominadas «detenciones arbitrarias»: aprehensiones de los jóvenes en la vía pública sin causa determinada y que dependen del criterio discrecional del policía, quien decide in situ el destino de quien considera sospechoso, pudiéndolo llevar a sede policial. La última estadística oficial de la Policía data de 2011 y fue obtenida a instancias de un pedido formal de diputados cordobeses (Coria y Etchichury, 2011). Su análisis permite concluir que en ese año hubieron 73.100 detenciones sin causa probada (200 por día), siendo los detenidos mayoritariamente varones ${ }^{2}$ (86\%) y jóvenes (alrededor del 70\% menores de 35 años). Para completar este perfil, una investigación realizada hace unos años indica que el 54 \% de los detenidos pertenece a «sectores sociales bajos» (Bolatti et al., 2013).

En síntesis, las detenciones arbitrarias y al hostigamiento policial en Córdoba recaen fundamentalmente sobre varones jóvenes de estratos sociales bajos, que viven en barrios que presentan alta «vulnerabilidad socio-residencial» (Bologna, et. al., 2017), es decir, condiciones deficitarias en la construcción de las viviendas, bajos niveles de ingreso del hogar, así como en lo referido a la educación y ocupación del jefe de hogar.

Los resultados que se reportan en este artículo, se enmarcan en un acervo de conocimientos construido en los siete últimos años de desarrollo de sucesivas investigaciones ${ }^{3}$.

El carácter brutal y sistemático del accionar policial cordobés dirigido a los jóvenes pobres ha sido profusamente documentado en la trayectoria de investigación antes mencionada, focalizando en distintas dimensiones: la relación entre las normas contravencionales ${ }^{4}$ y la carga punitivista de los imaginarios sociales locales (Bonvillani, 2015), la clave racializante de los procesos de etiquetamiento que justifican el accionar policial arbitrario (Bonvillani, 2019) y las restricciones en la circulación por el espacio público que sufren los jóvenes afectados por este hostigamiento policial continuado (Bonvillani, 2017).

En un trabajo anterior (Bonvillani, en prensa) se ha afirmado que las modalidades de accionar policial antes referidas, deben ser inscriptas en los dispositivos estatales de seguridad del gobierno provincial. Los mismos se basan, en líneas generales, en concepciones punitivistas de la cuestión securitaria, reducida a la protección de bienes privados y con una clara tendencia a no respetar los derechos humanos básicos.

De este modo es posible afirmar que en el último bienio la política de seguridad del gobierno de Córdoba se articuló como respuesta a la demanda represiva de la opinión pública hacia el Estado (Kessler, 2009), que a su vez deriva del sentimiento de inseguridad insistentemente alimentado por los medios de comunicación hegemónicos. Este proceso, propio de la modernidad tardía, tiene como motor el temor a perder los bienes materiales acumulados, que alimenta un clima de amenaza permanente, frente al cual las sociedades responden construyendo barreras materiales y simbólicas e intensificando todos los controles y castigos posibles hacia determinados «otros», considerados esencialmente peligrosos (Young, 2007) y, necesariamente, objetos de represión.

En consonancia con lo que se viene argumentando, el hostigamiento sostenido y la eventual detención de esos «otros» jóvenes pobres -construidos socialmente como los únicos responsables de la «inseguridad», permiten al gobierno provincial tranquilizar a la clase media cordobesa en el reaseguramiento de su propiedad privada. Con Zaffaroni (2007) podemos afirmar que se trata de una pieza ejemplar de «demagogia punitiva». 
A esta matriz de ejercicio del poder estatal referido a la cuestión de la seguridad, la denominaremos «estado policial cordobés» (Job, 2018). Además de los consignados, otro rasgo que caracteriza al estado policial cordobés es la presencia masiva y constante de la policía en los barrios, siendo en muchos casos el único rastro estatal en los territorios. ${ }^{5}$

En este marco, este artículo focaliza en los «sentidos subjetivos» (González Rey, 2002) que las víctimas construyen respecto de las experiencias de hostigamiento policial. Para ello, desde la perspectiva situada de los propios jóvenes que las padecen, se caracterizará dicha práctica policial a través de una categoría local: el «verdugueo». El mismo conjuga un conjunto de elementos simbólicos y cognitivos (descripciones, significaciones y explicaciones) sobre las rutinas policiales, así como la emocionalidad particular (Bonvillani, 2010) que estas experiencias despiertan en ellos y algunas pistas sobre los cursos de acción que les inspiran.

En síntesis, se argumenta en torno a la siguiente conjetura: el «verdugueo» expresa, a partir de la metáfora que contiene, el ejercicio a nivel microsociológico de poder del estado policial cordobés, articulando arbitrariedad, impunidad y espectacularización.

\section{Discusión teórica}

En Latinoamérica los jóvenes pobres son generalmente objetos de persecución y violencia policial. Como afirman varios autores (Reguillo, 2003; Cháves, 2005; Valenzuela Arce, 2019), en nuestras sociedades se refuerza un imaginario que les imputa la condición de enemigo interno, responsable inequívoco de la violencia y la inseguridad urbana y, consecuentemente, objeto de represión. El que se los considere de esta forma, justifica prácticas punitivas que van desde controles permanentes en la vía pública hasta desapariciones y muertes. En algunos países de la región, como México, Colombia y Brasil, esta problemática alcanza niveles tan dramáticos que ha motivado que se acuñara la categoría «juvenicidio» (Valenzuela Arce, 2015) para dar cuenta de los crímenes que sistemáticamente arrasan las vidas de los jóvenes a manos de las fuerzas de seguridad estatales y paraestatales.

En las últimas décadas en Argentina se ha desarrollado un campo de estudios sobre violencia institucional, con énfasis en las prácticas de hostigamiento policial que sufren los jóvenes de sectores populares. Diversas investigaciones han mostrado que la acción punitiva de las agencias de seguridad está focalizada en grupos sociales estigmatizados (Isla y Míguez, 2011) a los que pertenecen estos jóvenes. De este modo, las relaciones conflictivas con la policía marcan la sociabilidad juvenil en los barrios pobres de distintas ciudades argentinas (Di Leo y Camarotti, 2013; Medan, 2017). Las prácticas policiales en estos contextos configuran una rutina cotidiana caracterizada por la persecución, el maltrato físico y simbólico (Kessler y Dimarco, 2013), pudiendo llegar incluso a la desaparición forzada y las ejecuciones de jóvenes pobres (CELS, 2016).

El hostigamiento es la categoría analítica que suele utilizarse en la literatura local para describir las diversas formas que adquiere lo que la policía hace con grupos de sectores populares -fundamentalmente jóvenes- en las calles de las ciudades argentinas: «Estas prácticas se caracterizan por el abuso, el maltrato, la humillación, la arbitrariedad, discrecionalidad y la transgresión del marco legal» (Tufró, 2019, p. 118).

Estas modalidades pueden ser interpretadas como una suerte de secuencia que se vuelve rutinaria para algunos jóvenes: ser detenido transitoriamente porque el agente los intercepta en la calle, ser interrogados para que se identifiquen o presenten papeles que acrediten la propiedad de bienes, ser «cacheados» en sus cuerpos o requisadas sus pertenencias. Este micro proceso que se da generalmente en la vía pública, puede concluir o no en la demora/detención en la sede policial.

A los fines de un encuadramiento de lo que se quiere designar con «hostigamiento policial», se tendrá en cuenta que:

-puede tratarse de episodios aislados en la vida de un joven, así como de una persecución sistemática; -puede empezar y terminar en el espacio público o incluir la detención policial;

-estas rutinas policiales suponen un gradiente de violencia que va desde el plano simbólico al físico, y 
viceversa, pudiendo incluso terminar en la muerte: «el hostigamiento remite a intensidades de violencia, discrecionalidad y arbitrariedad policial que pueden ser antesala de hechos de violencia más extremos» (Pita, 2019, p. 88).

En el caso cordobés investigaciones recientes han mostrado que las rutinas policiales tienden a ser abusivas, violentas y arbitrarias, ya que operan bajo «criterios de selectividad policial» (Lerchundi y, Bonvillani 2018), basados en prejuicios que constituyen en víctimas preferentes a determinados grupos sociales y etarios.

En la literatura anglosajona, especialmente estodounidense, el sintagma «Stop and frisk» alude a prácticas policiales análogas a las aquí descriptas. En aquel contexto la particularidad de esta acción de «Parar y registrar» es que parece estar especialmente destinada a hombres afroamericanos, siendo expresivas de la «subordinación racial» ${ }^{6}$, es decir, el uso de sistemas sociales, incluyendo la ley, para oprimir o controlar una minoría racial (Butler, 2014, traducción propia). El autor de referencia ensaya una suerte de genealogía de estos procedimientos de violencia racializada, para remontarse a los linchamientos que eran comunes en la época de la esclavitud en Estados Unidos, los cuales remiten a la presencia de verdugos que los ejecutaban.

En resonancia, el «verdugueo» es una categoría nativa que los jóvenes de los barrios populares de Argentina usan para ponerle nombre a la experiencia encarnada de hostigamiento. Es por ello que no ha recibido tratamiento como categoría conceptual, sino que ha sido mencionada descriptivamente en algunos reportes de investigaciones como los de Suárez y Bouilly (2012) y las reflexiones de Rodríguez Alzueta (2017).

Según el diccionario de la Real academia española, «verduguear» es un verbo transitivo de uso coloquial en Argentina que significa atormentar a alguien, humillarlo. Le corresponde el sustantivo verdugo: persona encargada de ejecutar la pena de muerte u otros castigos corporales impuestos por la justicia. De este modo, se trata de una creación del discurso informal y cotidiano que recoge la esencia de su etimología: el sentimiento de estar a merced de un verdugo que tortura, el policía.

Como se anticipó en la Introducción, el propósito de este trabajo es focalizar en el «sentido subjetivo» (González Rey, 2002) que estas experiencias tienen para las víctimas. Por sentido subjetivo se entenderá la «unidad constituyente de la subjetividad que integra aspectos simbólicos, significados y emociones en una nueva organización, dentro de la cual estos elementos no tienen relaciones de causalidad» (González Rey, 2002, p.113).

Desde esta perspectiva conceptual el sentido subjetivo es un tipo de unidad psicológica que integra aspectos simbólicos y de significación con las emociones que adquieren las experiencias para los sujetos.

Se trata, en consecuencia, de una cualidad que constituye la particularidad subjetiva en tanto capacidad generativa de significaciones de los sujetos. Dicha capacidad generativa se expresa de manera privilegiada en el campo del lenguaje. Es por ello que en este artículo se presta especial atención a la producción del significante «verdugueo» como condensador vívido de la experiencia de hostigamiento policial, mostrándolo como una producción de sentido singularizada en el marco de un proceso de subjetivación juvenil. En esa línea, los interrogantes que sirven de marco para el análisis propuesto son: ¿cómo se inscribe subjetivamente esta experiencia? ¿Cuáles son las huellas que produce en las subjetividades de estos jóvenes?

Una dimensión que tensiona este trabajo se refiere al tipo de ejercicio de poder gubernamental en el que se soportan estas relaciones entre jóvenes y policías. La arbitrariedad y la brutalidad que caracteriza al verdugueo nos arrojan a una pregunta que contiene una paradoja: ¿cómo es posible que en un supuesto estado de derecho democrático como el argentino se violen sistemáticamente derechos humanos de tantos ciudadanos? El concepto de «estado de excepción» (Agamben, 2005) permite explicar la suspensión del estatus jurídico de determinados individuos considerados una amenaza para el orden o, sencillamente, no integrables a él. Aunque parezca un rasgo característico de los totalitarismos, el autor italiano señala que se trata de las formas de gobierno que adquieren las democracias contemporáneas. Esta puesta entre paréntesis del propio orden jurídico que supone el estado de excepción es, contradictoriamente, un hecho jurídico que dispone el estado. Esta ley es ahora determinada por el soberano en su capacidad de establecer lo que considere conveniente. Como se desplegará 
a lo largo del trabajo, es en ese punto en el cual se ancla el ejercicio de poder del verdugo: poder de vida y muerte. El verdugueo es posible en el marco de un estado de excepción, donde la tortura o incluso la eliminación de algunas vidas no será objeto jurídico, porque se trata de existencias desechables, eliminables.

\section{Diseño metodológico}

En el marco de una estrategia metodológica cualitativa y a lo largo de siete años de investigación, se implementaron técnicas conversacionales (Vallés, 2007), desplegadas en diversas situaciones de interacción con jóvenes de sectores populares de la ciudad de Córdoba, como de otras localidades del interior provincial. Puede afirmarse que, aunque el diseño metodológico no se ajusta a la Etnografía en sentido estricto, sí está inspirado en el modo etnográfico de habitar y compartir con estos jóvenes sus mundos cotidianos de experiencia, en sus barrios, sus escuelas, en las acciones contenciosas que se articulan dentro de lo que podría denominarse «campo anti-represivo cordobés». La ya mencionada Marcha de la Gorra (en adelante, MDG) ocupa un lugar central como vertebradora en este campo, ya que se trata de una manifestación colectiva de protesta callejera, que activan los jóvenes cordobeses ininterrumpidamente desde 2007 en las calles céntricas de Córdoba para resistir y denunciar el hostigamiento, las detenciones arbitrarias y los casos de gatillo fácil.

En detalle, las distintas técnicas de producción de datos que se han desarrollado son:

-entrevistas en profundidad (Vallés, 2007), realizadas a los jóvenes que se articulan en la MDG a través de agrupaciones estudiantiles, organizaciones barriales, colectivos artísticos y culturales, organizaciones no gubernamentales, etc. De acuerdo con los criterios propios de la metodología cualitativa, el número de entrevistas realizadas resultó de la aparición de «saturación», es decir, redundancia en las respuestas obtenidas. Atendiendo al muestreo teórico propuesto por la Teoría Fundamentada en los hechos (Glasser y Strauss, 1967), se tuvieron en cuenta como criterios de selección de los entrevistados: el género, la pertenencia organizativa, la exposición a experiencias de detención policial y la trayectoria de participación en la acción de protesta en estudio. El rango de edad de los sujetos va de los dieciséis a los veintiocho años. A lo largo de la trayectoria investigativa considerada se tomaron un total de cuarenta y cinco entrevistas en profundidad.

-»Conversaciones en marcha» (Bonvillani, 2016): diálogos informales entre investigadores y todos los incluidos en el campo de la MDG, es decir, los marchantes, transeúntes, curiosos. Estos intercambios que se inician a instancias de la invitación del investigador, están atravesados por las atmósferas subjetivas y colectivas propias de una manifestación de estas características, que van desde aspectos prácticos como la dificultad de moverse en las columnas que tienen muchas banderas, hasta la intensidad sensorial y la afectación anímica de la que todos los que allí estamos somos parte. Son deudoras de las «conversaciones informales» (Vallés, 2007), ya que se plantean en el propio curso del estar-ahí-etnográfico, prescindiendo de la fijación de un encuadre previo de trabajo, como en el caso de las entrevistas.

-Talleres grupales de reconstrucción de experiencias, intercambio y construcción colectiva (Bonvillani, 2017), que se realizaron en establecimientos educativos de nivel medio de la ciudad capital y otras localidades de la provincia de Córdoba, durante 2016. Inspirados en las concepciones socio-educativas de la Educación Popular, en los talleres se utilizaron recursos grupales y lúdicos, para favorecer la expresión y la comunicación de los jóvenes sobre sus experiencias en torno a la policía. En este artículo se consideran los registros de los cinco talleres desarrollados en un Instituto Provincial de Educación Media (en adelante, IPEM) de una localidad cercana a la capital cordobesa.

La integración de estas distintas técnicas cualitativas se produce siguiendo el criterio de «triangulación intratécnica», que permite poner en diálogo los aportes específicos de cada una, a saber: las entrevistas en profundidad son interacciones verbales y gestuales pautadas de antemano con el entrevistado, en un espaciotiempo distinto de la movilización, mientras que las conversaciones en marcha permiten captar la inmediatez subjetiva de quien vive la experiencia in situ, ya que los marchantes son abordados en el mismo momento en que realizan la acción, intentando con ellos pensar sobre esta y acompasar la tentativa reflexiva con el caminar, saltar, gritar, cantar, bailar, etc. Por lo tanto, son más breves y focalizadas que las demás técnicas conversacionales 
utilizadas. Los talleres permiten potenciar la interacción de los jóvenes entre sí y con un investigador que los coordina, quien propone disparadores para la discusión y favorece la producción de preguntas y el diálogo entre los participantes, que queda registrado textualmente por un investigador-observador.

En la citación de los fragmentos se utilizan seudónimos para garantizar el anonimato y se consignan algunos datos relevantes como la edad, la pertenencia institucional del hablante, así como la técnica y el año en el que fue implementada, para situar la posición discursiva y las condiciones de producción de la información.

El análisis se orientó a la construcción de ejes y categorías a partir de las recurrencias y divergencias encontradas en el trabajo de campo, con el apoyo del paquete informático Atlas.ti.

\section{Resultados}

El estudio realizado permite observar que el verdugueo aparece como una forma de tortura que combina el empleo de la fuerza física sobre el cuerpo (golpes, tirones, empujones, etc.), con insultos y distintas ofensas verbales, destinadas a atormentar, humillar y degradar a los jóvenes pobres en su condición de seres humanos. Reviste, además, un carácter arbitrario e impune, en tanto no necesita más justificación que lo que el verdugo quiere y determina. A modo de síntesis introductoria se presentan los siguientes fragmentos discursivos:

«Martín: Si te paran y te hablan bien es como te transmite más seguridad de que no te va a pasar nada...pero si te empiezan, digamos a tratar mal...cómo decirlo...hacer...dar a notar su....tratar de ejercer su...

José: en palabra de juerga (jerga) sería «verduguear»

Martín: Claroo! Ahí está....

Entrevistadora: ¿qué es verduguear?

José: Verduguear es como maltratarte simplemente....

Martín: sin una razón notable...

José: sin una razón notable...simplemente.

Entrevistadora: Cuándo un policía te verduguea, ¿qué te hace?

José: Te trata mal...

Darío: Como quiere...

José: como quiere!

Martín: en vez de decirte «abrí las piernas»...te pegan una patada....

José: en las piernas....

Martín: te pegan una patada en este lado (se golpea el lado interior del pie) por así decirlo, para que se abran...

José: por ejemplo «dale, dale pibe...cerrá las...». A mi hay algo que me pasó, bueno, cuando les mostré el documento todo, me dijeron «Dale, dale, vuelen! Si no la próxima vez que los veamos acá los llevamos»(Martín, Darío y José, raperos, entrevista grupal en Jornada «Córdoba no baja» ${ }^{8}$, 2019)

«en realidad quizás no se detengan a los pibes pero si se lo suben al móvil y los dan vuelta por los barrios. Por ejemplo, el verdugueo sigue estando en los barrios, no ha frenado la violencia con los pibes»(Mario, cantante popular, entrevista en profundidad, 2017).

«hoy en día no te los llevan solo, te los golpean, los torturan en la forma en que los hablan» (María, familiar de un joven víctima de gatillo fácil, conversación en MDG, 2014).

Frente a estas experiencias de hostigamiento constante, los propios jóvenes parecen estar preguntándose: ¿por qué? Los motivos que le atribuyen son en muchos casos los prejuicios del policía respecto de atributos que ellos portarían a simple vista, una atribución de sospecha anticipada y prevalente, no por una acción cometida, sino por ser quien se es:

«en la misma calle hemos tenido casos de compañeros de murga que han quedado detenidos solamente por portación de rostro o porque se le cantó al policía» (Carlos, murguero, entrevista en profundidad, 2013). 
«podemos estar caminando sin hacer nada y puede venir un policía porque nos ve sospechosas y detenernos. Ahí viene la estigmatización porque está dirigido hacia un sector de la sociedad que tiene determinadas características en su forma de vestir, en sus gustos musicales, en su forma de hablar» (Inés, estudiante, entrevista en profundidad, 2015).

Los jóvenes de sectores populares de Córdoba, han acuñado la expresión «portación de rostro», para designar la relación automática e incuestionada entre apariencia física y peligrosidad que se les atribuye desde el sentido común. La metáfora resignifica la canónica «portación de antecedentes», como criterio de sospecha policial en relación a la producción de un delito. Este «rostro» (el identikit del delincuente) remite a características vinculadas al fenotipo, básicamente una oscura pigmentación de la piel, aunque sus significaciones no se agotan en esta línea de sentido: «Se revela así lo imbricado del proceso de racialización a nivel local, puesto que tanto lo biológico (rasgos orgánicos, cuerpo), como la gestión del propio cuerpo (apariencia, corporalidad), son decodificados en las interacciones cotidianas a partir de un régimen de sentido hegemónico que implica categorizaciones sociales y culturales (Bonvillani, 2019, p. 339).

La arbitrariedad policial, ampliamente reportada en estudios de este campo (Bonvillani, 2017; Pita, 2019), aparece subyaciendo en las significaciones construidas por los jóvenes cuando intentan explicar-se algún atisbo de orden causal ofrecido por el propio policía para justificar su accionar. Se observan aquí «teorías implícitas» (Castorina et. al., 2005) que permiten suministrar explicaciones acerca de las situaciones de hostigamiento que los jóvenes viven a partir de las construcciones simbólicas que ellos producen en los escenarios de interacción social. Es por ello que son formas de conocimiento de sentido común, siendo tácita su lógica argumentativa. En los siguientes registros esta lógica reproduce discursivamente la propia alocución del policía:

«acostumbrado a que la policía puede hacer eso, puede venir y bardearte9 , y preguntarte 'vos que estás haciendo acá' o ‘para mi vos andás robando’ o ‘están al pedo ustedes, por eso hacen música’ y que se yo, todo este tipo de cosas que las dicen impunemente digamos»(Lautaro, murguero, conversación en MDG, 2014).

«A mí lo primero que se me ocurrió, porque yo ya estaba como metido en este tema, es: ¿y por qué yo? Si no estoy haciendo nada, estoy esperando un amigo, y lo que me respondieron fue 'porque yo quiero'. $Y$ bueno, tuvimos que darle los documentos» (Esteban, integrante grupo juvenil de una ONG, entrevista en profundidad, 2015)

«En Nueva Córdoba vos caminás, te pasa el patrullero, va, pega la vuelta manzana y te para en la otra esquina...y siempre buscando si tenemos droga, qué andamos haciendo y a lo último te terminan diciendo ándate a tu casa, no te queremos ver acá, si te vemos acá, te llevamos y te hacemos cagar’» (Damián, joven de barrio popular, entrevista en profundidad, 2018)

«yo estaba volviendo a la casa de mi abuela y era de noche y me pego una patada y me decía 'sácate la mochila, estás robando’. Yo volvía de entrenar de Córdoba y me trataron de chorro, me pegaron una cachetada. Otra vez me pasó cuando iba con la moto. Ya te tienen junado, te tenés que quedar callado»(Noel, estudiante secundario, primer Taller IPEM , 2016)

Más allá de que el estar exceptuado de autojustificarse es inherente al ejercicio de poder-verdugo, en los fragmentos antes citados encontramos un esbozo de argumento de justificación de parte del policía que justamente verifica el núcleo de sentido que define la arbitrariedad: su propio deseo opera como razón suficiente para producir su conducta.

Es posible que lo intolerable -en un sentido tanto cognitivo como emocional- del estatuto de la arbitrariedad policial, aparezca en las significaciones de quien lo padece en carne propia, como una imposibilidad para ponerle un nombre: lo que queda es reproducir la pieza discursiva inmediata a la vivencia de la violentación simbólica y física, manifestando casi una dificultad para representarlo de otro modo. Así operan las teorías implícitas, «sin que el sujeto sea consciente de las mismas porque no puede tematizar sus conocimientos, simplemente los utiliza» (Castorina et. al., 2005, p. 204). Este carácter pragmático de las teorías implícitas se 
manifiesta en este caso en la comprensión de las significaciones simbólicas de la arbitrariedad e impunidad policial a través de las consecuencias prácticas que las mismas tienen para la preservación de la integración física y/o de la propia vida. Los jóvenes mencionan cursos de acción en el marco de estas interacciones rutinarias: acostumbrarse, darle lo que piden, agachar la cabeza, quedarse callado. En fin: aceptar estas condiciones calibrando los riesgos de experimentar los efectos potencialmente letales si se resisten.

En última instancia lo que se acepta resignadamente es no desafiar al verdugo, no des confirmarlo en su poder. Como sostiene Le Breton (2009) la mirada es una instancia muy sensible en la interacción con aquel que se considera superior a los demás. Entonces, desde la perspectiva del verdugo, el sentirse observado puede resultar inadmisible, en tanto indicativo de cuestionamiento de su autoridad inmanente. En el saber hacer que se va incorporando subjetivamente a partir de la experiencia de hostigamiento y persecución diaria, los jóvenes gestionan su propia mirada como una estrategia de supervivencia:

«Yo directamente ni los miro, yo miro el móvil, me quedo ahí, le contesto lo que les tengo que contestar y nada más, ni los miro, nada...»(Damián, joven de barrio popular, entrevista en profundidad, 2018)

«Martín: Porque de chico, a los 13 años me pasó, estaba volviendo del colegio, de educación física...y miré a un policía, por mirar nomás, porque me parecía raro ver un policía a esa hora y lo miré...hice, no sé, 20 metros después de que lo pasé...y me paró.

Entrevistadora: Porque lo miraste....

Martín: Sí, eso fue lo irónico, que fue porque lo miré. No sé si me vieron sospechoso o qué, pero ves un chico de zapatillas volviendo del colegio...es irónico...

Darío: Igual, también hay veces que pases y no lo miras, tratás de no mirarlo y pensás que estas escapando de ellos...que tenés algo». (Martín y Darío, raperos, entrevista grupal en Jornada «Córdoba no baja», 2019).

Otras significaciones acerca de la arbitrariedad e impunidad con las que se manejan los policías, hacen eje en el ejercicio de un dominio sobre el cuerpo del joven, no solo por la brutalidad con que lo manipulan para requisarlo -como motivo explicitado- y para someterlo -como finalidad implícita del verdugueo-, sino en la determinación acerca de los lugares que pueden o no ocupar en el espacio público. En última instancia, el cuerpo es tratado como un objeto en disponibilidad de ser escudriñado, revisado, abusado y retirado de la vista.

«Una vez me pararon también cerca de la Plaza de la Intendencia y me dijeron 'te llego a ver de vuelta y te llevo', y eso es algo que te dicen todo el tiempo, te paran y lo último que te dicen es 'te veo de vuelta y te llevo'. Claro, 'agradecé que no te llevo y andá encerrate hasta que yo me olvide de tu cara' (afirma como reproduciendo lo que pensaría el policía)» (Esteban, integrante grupo juvenil de una ONG, entrevista en profundidad, 2015)

«nos quedamos en una esquina tomando gaseosa. Cae la policía y no teníamos documento. Y nos llevaron a la comisaría. Nos dejaron ahí una noche en un calabozo. Yo, asmático! Empecé a sentirme muy mal. Éramos unos pibes y nos encerraron!» (Benicio, joven de barrio popular, entrevista en profundidad, 2015)

Estas prácticas policiales que impiden a los jóvenes permanecer en puntos determinados del centro visible de la ciudad de Córdoba (Plaza de la Intendencia, La Cañada, Barrio Nueva Córdoba), se constituyen en verdaderas «barreras materiales y simbólicas que configuran una cartografía de prohibiciones del espacio supuestamente público» (Bonvillani, 2017, p. 121).

Como puede observarse, el poder policial debe hacer sentir sus efectos de sometimiento inmediato en el cuerpo. Pero con eso no parece alcanzarle: el tormento psicológico de la intimidación debe proyectarse más allá de la interacción cara a cara en la calle. 
En última instancia, la tortura verbal a la que están sometidos los jóvenes es inherente a un poder policial que para funcionar necesita actualizar subjetivamente en la vivencia de la víctima su condición de tal, no sólo en el aquí y ahora, sino como amenaza futura:

«en los barrios, que la policía, va y amenaza, y les dice «te vamos a hacer desaparecer, como a tal» (Florencia, militante de organización política, entrevista en profundidad, 2015).

Los efectos del verdugueo deben quedar inscriptos subjetivamente como terror para que no haya dudas de qué lugar ocupa cada uno en la escena y cómo debe comportarse en consecuencia. En tal sentido, las significaciones simbólicas que se despliegan a continuación en los relatos de los jóvenes, muestran que las prácticas rutinarias de la policía responden en última instancia a la búsqueda de la «producción/reproducción de poder, la construcción de mando y la imposición de autoridad, así como en la producción de dominio sobre un territorio y de poder de gobierno sobre una población» (Pita, 2019, p. 91).

Las huellas de este significado institucionalizado aparecen en algunos fragmentos discursivos analizados deslizándose en las concepciones de sentido común acerca de lo que se espera a nivel formal de la policía en un estado de derecho: «el trabajo de ellos es hacer cumplir la ley» o «cuidar al barrio de». Sin embargo, esta vertiente de sentido sucumbe ante la sustancia del verdugueo policial que emerge a partir de vivenciar la experiencia directa: un excedente de violencia, un mal trato en el procedimiento, un abuso de poder, como se observa en las siguientes citas textuales:

«Calculo que nadie acá no se haya comido alguna bolaceada de la policía ¿no? Una verdugueada, una ninguneada, una denigrada, que es lo que hacen, una atrás de la otra: que te das vuelta, y la mano atrás del móvil, y separa los tobillos...» (Lautaro, murguero, conversación en MDG, 2014).

«Que te traten mal, porque en realidad ellos tienen el poder de tratarte mal sin que vos hagas nada, porque si vos hacés algo te pueden meter en cana. Eso es abuso de poder, eso es el verduguear, eso me parece que es lo que más molesta, porque en realidad si lo hicieran de buena manera... Supongamos que cada barrio es un jardín, y cada uno va a cuidar su jardín, a mí me gusta mi barrio, yo cuido a mi barrio, y si yo veo a alguien que «no me gusta» (entre comillas) en mi barrio, y sé que puede andar echando moco, voy a ir y voy a hablar, ‘eh chabón ¿qué onda?’, y está bueno que se haga respetar el barrio, por ejemplo, pero no me parece para nada bien de que lo hagan de esa forma» (Esteban, integrante grupo juvenil de una ONG, entrevista en profundidad, 2015).

«el trabajo de ellos es hacer cumplir la ley, pero no tratándote como un perro. Se creen superiores a todos» (León, estudiante secundario, cuarto Taller IPEM, 2016).

Este excedente en el ejercicio del encargo social, que la policía asume en términos de monopolizar el uso de la violencia en un estado de derecho, anida en la esencia misma de la verdugueada. No se trata de cumplir una tarea social como cualquier otra, sino de encarnar una superioridad incuestionable que es autoevidente para justificar la arbitrariedad de la acción. Entonces, verduguear se ubica en la discursividad de las víctimas en la misma línea de sentido que denigrar, ningunear, basurear. En síntesis: alude a la construcción del otro «victimizable» como una naturaleza inferior.

Ser negro, ser nadie, ser basura, ser un perro, supone distintos matices de una misma trama de sentido: ser des-reconocido como un par humano. Habilita la mortificación -e incluso el aniquilamiento- sin mayores explicaciones: «Negar la condición de humanidad, es en sí una forma de borramiento subjetivo en el plano simbólico, pero opera estratégicamente como construcción para fundamentar su destrucción material» (Bonvillani, en prensa, p. 26).

En esta línea de sentido, la policía de Córdoba en 2014 implementó una modalidad de detención denominada «corralito humano» ${ }^{10}$. Como puede observarse en la Figura 1, a los jóvenes demorados se los hacía sentar en la calle y permanecer en un cuadrilátero delimitado por vallas a la vista de todos. Siendo los corrales utilizados 
específicamente para contener animales, estas prácticas constituyen la puesta en acto de la narrativa de reducción a la animalidad que antes se señaló, en tanto esencia del componente de tortura y sometimiento a la indignidad que anida en el ninguneo.

\section{Figura 1. \\ Corralitos humanos}

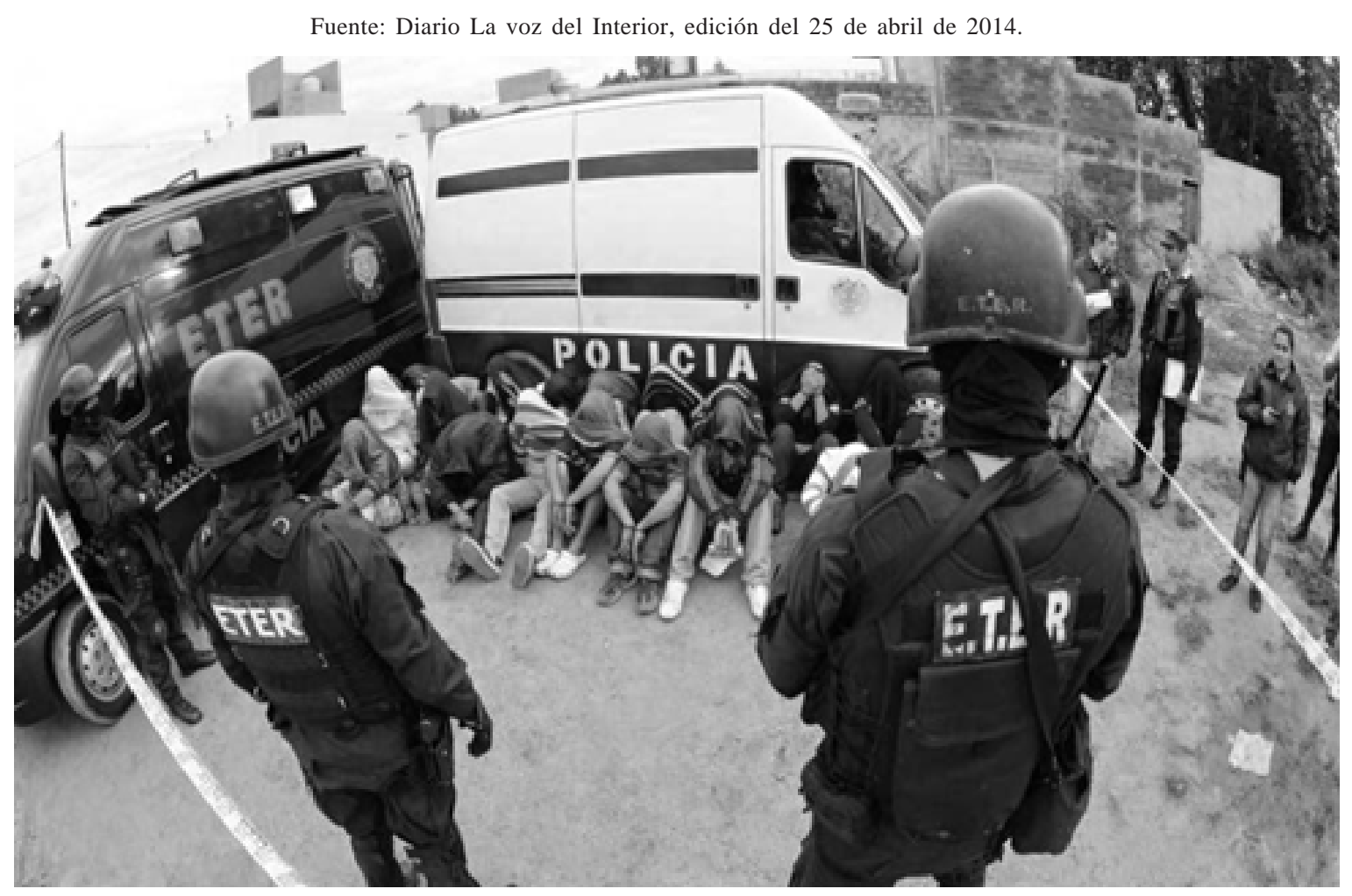

Disponible en: https://www.lavoz.com.ar/ciudadanos/allanamientos-y-corralitos-humanos

En el análisis que Foucault (2002) propone en su célebre «Vigilar y castigar», ubica un momento premoderno en el régimen del castigo, en el cual el mismo adquiere la forma de un «espectáculo punitivo». Es básicamente un dispositivo de teatralización donde la exhibición del culpable, se pone al servicio de la necesidad de sangre de la multitud, tranquilizando una demanda de venganza.

Más allá de las diferencias evidentes respecto de los suplicios a los que los condenados eran sometidos en aquel entonces, llama la atención la pervivencia de esta búsqueda de poner en escena el tratamiento de aquel considerado culpable. La posición de los cuerpos inclinados hacia adelante e inmóviles, las muñecas esposadas, las caras tapadas con sus ropas o con unas manos desapacibles e impotentes, la presencia entre robótica y espectral del policía, cierran un cuadro que grafica sometimiento extremo. Cuerpos a merced del verdugo, ofrecidos a la mirada social que viene a garantizar que el efecto de culpabilización se inscriba en la subjetividad del joven, a través de la humillación y la vergüenza que esas miradas sancionatorias producen como afectación emocional predominante.

Concomitantemente, en los testimonios de los jóvenes con los que se trabajó, la vergüenza es una emocionalidad que tiñe la experiencia del verdugueo:

«Que te agarren a las 12 del mediodía y toda la gente ahí mirando y los que pasan en el ómnibus saquen 
la cabeza... nadie te va a creer que no hiciste nada, piensan que si nos paran es por algo» (Leandro, estudiante secundario, cuarto Taller IPEM, 2016)

«andá a preguntarles porque te paran, si siempre es el mismo, ¿para qué te para? Te hace pasar vergüenza» (León, estudiante secundario, cuarto Taller IPEM, 2016)

«Damián: y....la gente se pone a mirar por ahí, te da cosa...porque ya te mira con otro ojo, porque como siempre pasabas por ese mismo lugar y te ven que te paran ahí...y ya piensan cualquier cosa, que andamos robando o algo así. Ya nos miran con otros ojos.

Entrevistador: ¿Y eso pasa en algún otro lugar o ahí nomás?

Damián: No. Porque acá en la villa ya nos conocen de vista, o ya nos conocen algunas personas, ya saben que no andamos en nada malo. Una vuelta nos pararon a mí y a tres amigos, acá cerca de mi casa a tres cuadras más para allá, yendo para la plaza. Y los vecinos saltaron por nosotros, aunque no nos conocían directamente, pero nos conocían de vista y saltaron, dijeron «no, si estos chicos son buenos, no andan haciendo nada, no andan robando, nada. Siempre pasan por acá»

Entrevistador: ¿Sabían que eran de acá del barrio?

Damián: Claro, sí

Entrevistador $\dot{¿}$ Y eso en el centro...?

Damián: No, eso en el centro no pasa, te quedan mirando como diciendo 'estos andan robando' o algo así» (Damián, joven de barrio popular, entrevista en profundidad, 2018)

Más allá de que ocultar la cara del detenido es parte del procedimiento policial, en la Figura 1 se advierte que la vergüenza que los jóvenes pueden estar experimentando se evidencia en el gesto desesperado de cubrirse el rostro con ambas manos. Es una metáfora de la mortificación por la vergüenza que la humillación produce, en la cual cubrirse es un recurso necesario para evitar la identificación pública de culpabilidad. En efecto, la vergüenza es una afectación emocional que se vincula con la intimidación y la humillación física y con un «código moral compartido que se ha visto transgredido» (Jasper, 2012, p. 50).

En la escena del verdugueo aparece siempre el vecino o el transeúnte juzgando, es decir, encarnando en su mirada una sanción moral. Ese otro funciona sellando el oprobio al que somete el policía, porque cierra el círculo de la humillación y lo justifica. La mirada de ese otro opera una suerte de garantía de la conducta del policía que verifica una vez más la equivalencia simbólica joven pobre=peligroso» (Bonvillani, 2015). Aún en las situaciones donde los vecinos actúan de modo contrario, el argumento para hacerlo se basa en construcciones de sentido común de carácter moralizante («estos chicos son buenos, no andan robando») y no en la reprobación de un procedimiento policial que vulnera derechos.

La humillación física a la que somete el policía al joven se expande y profundiza con la vergüenza, cuando el acto de violencia e intimidación ingresa en el circuito de la mirada y el juicio de los otros porque se hace público. En tal sentido, Nussbaum (2014, p. 436) señala que la humillación es el «rostro público activo de la vergüenza: supone la imposición hostil a otros del sentimiento de vergüenza».

Dicho sentimiento que el verdugueo produce en las víctimas, conjuga la humillación a la que las somete el policía y la visibilidad pública que produce su condición espectacular:

«Cuando yo no sabía nada, veo toda esa opresión que yo viví, ese sufrimiento, toda esa humillación que yo sentía, que creo que yo inclusive pensaba que yo la merecía, que yo era el culpable por eso, que estaba bien, porque yo era el culiadito ${ }^{11}$ culpable de todos los males de la sociedad, porque así te hacen sentir. Ya era tanto el hostigamiento todos los días, que te va pasando, las veces que te llevan en cana, todo eso, 
que te hace sentir eso. Entonces vos, prácticamente te subís solo en el móvil»(Luis, militante organización territorial, entrevista en profundidad, 2015).

\section{Conclusiones}

El hostigamiento es una categoría técnica muy precisa para describir las prácticas represivas de la policía, pero no alcanza a mostrar las afectaciones emocionales y las significaciones simbólicas con que la experiencia se inscribe en las subjetividades de quienes lo padecen en primera persona, como lo hace el «verdugueo».

El verdugueo es el nombre de una creación colectiva del discurso que muestra la apropiación subjetiva de la vivencia de mortificación física y emocional que producen las acciones policiales rutinarias en las víctimas jóvenes.

En el plano micro-sociológico es una pieza de ejercicio de poder: cada interacción entre la víctima y su verdugo es ocasión de actualizar y confirmar la sumisión del primero sobre el segundo. La ceremonia del verdugueo sirve para inscribir en la propia carne del joven el significado profundo de la arbitrariedad policial: la acción no requiere otra justificación que el deseo del verdugo. La propia racionalidad contradictoria con un marco legal que caracteriza a la arbitrariedad y la impunidad policial, limita la posibilidad de darle algún sentido explicativo a dichas prácticas, más allá del mero ejercicio del poder policial. Aunque los jóvenes no puedan objetivar con claridad las razones del verdugueo, lo que sí poseen es un saber hacer con él: no mirar a los ojos a los policías, quedarse callados y agachar la cabeza. Actuar el sometimiento confirmándolos en su poder se constituye en una estrategia de supervivencia inmediata, aunque en otros planos se reserven prácticas con sentidos de confrontación y resistencia, como en la Marcha de la Gorra.

En el núcleo de sentido subjetivo del verdugueo se encuentra el padecimiento emocional que conjuga humillación y vergüenza. La reducción a una condición no humana, se expresa en distintos agravios que lesionan su dignidad, produciendo un quebranto emocional que potencia el sometimiento.

Conceptualmente la vergüenza es una emoción que deriva de la autopercepción de inadecuación frente a un deber ser social. En este caso proviene de ser señalado como culpable de un delito por el solo hecho de ser de algún modo, «portación de rostro» según categoría local. Si lo que avergüenza es en última instancia el propio ser: ¿cuál sería la tarea subjetiva a emprender para no ser etiquetado como culpable y evitar el verdugueo? La respuesta nos arroja a un borramiento de la propia subjetividad juvenil popular que insiste en el sentido aniquilante del verdugueo.

La verdugueada no solo son golpes, insultos y maltratos en el aquí y ahora: es la amenaza de continuar y profundizar esas acciones sobre el cuerpo y la subjetividad del joven a futuro.

El carácter psicológico del suplicio actúa a modo de plus del efecto intimidatorio y represivo, ya que es un más allá de la experiencia de encuentro cara a cara entre el joven y el policía. Proyecta sus efectos en términos de francas limitaciones para el usufructo del espacio público (Bonvillani, 2017), cercenando la libertad de movilidad, generando aislamiento y restringiendo el derecho de acceso a la escolaridad y al empleo, por ejemplo. Esta cartografía de prohibiciones se inscribe subjetivamente al modo de esquemas representacionales de los lugares permitidos/prohibidos y opera limitando el disfrute de los bienes de la ciudad consagrados en lo formal.

La línea de significación por la cual el cuerpo del joven se ubica a merced de un verdugo, cristaliza el máximo grado de sometimiento y permite conjeturar la configuración de subjetividades juveniles disminuidas en su capacidad de agencia. La creación y uso del sustantivo «verdugueo» para nombrar la escena de tortura es muy potente a nivel simbólico porque evidencia ese excedente de mortificación: al verdugo no le basta con cumplir su trabajo, ya que debe además garantizar su propia producción/reproducción como tal. Para lograr su eficacia, la escena debe ser pública y adquirir carácter espectacular, como en los corralitos humanos. El verdugueo es una práctica necesariamente multi-corporal: el verdugo, su víctima y los otros que, sancionando con su mirada, garantizan la eficacia simbólica de la ceremonia como ejercicio de poder policial. El tormento consiste en 
parte en ser objeto de espectáculo, satisfaciendo la demagogia punitiva y cerrando el círculo de humillación y vergüenza.

\title{
Notas
}

\begin{abstract}
${ }^{1}$ Expresión originalmente acuñada por organismos de derechos humanos en Argentina, alude a los decesos producidos a manos de fuerzas de seguridad, especialmente policiales. Generalmente se presentan como un accidente o el producto de un enfrentamiento, para encubrir que se trata de asesinatos en el marco de la comisión de una ejecución extrajudicial. Aunque la metáfora refiere al uso de armas de fuego, concierne de modo global a todas las muertes producidas ilegalmente por las agencias de seguridad del estado.
\end{abstract}

${ }^{2}$ Si bien las prácticas de hostigamiento policial tienen como víctimas preferentes a varones, en varios de los registros de las investigaciones que dan origen a este artículo aparecen reportes de mujeres de acoso policial de carácter sexual. Debido a las particularidades que estos procesos de violencia revisten, en orden a los evidentes atravesamientos de dominación de género que los caracterizan, su tratamiento específico excede los límites de este artículo.

${ }^{3}$ Esta trayectoria de investigación comienza en 2012 con el proyecto «Grupalidades juveniles y politicidad. Explorando los sentidos políticos de las prácticas culturales colectivas de los jóvenes de sectores populares cordobeses». Durante 2014-2015 se desarrolló el estudio La «Marcha de la Gorra» como experiencia de subjetivación política de jóvenes de Córdoba (Argentina), desde 2016 a 2018 se continúa con «Diez años de la Marcha de la gorra: memorias de una lucha juvenil cordobesa». En la actualidad, se encuentra en desarrollo el proyecto «Militancias juveniles cordobesas». En todos los casos, bajo la dirección de Andrea Bonvillani, con subsidios de Secretaría de Ciencia y Técnica de la Universidad Nacional de Córdoba. En 2019 se conforma el Grupo de Estudio «Violencia institucional, Resistencias y Militancias juveniles», radicado en el Instituto de investigaciones psicológicas (CONICET) en la Facultad de Psicología de la mencionada universidad. Las modalidades represivas a las que la policía cordobesa somete a los jóvenes de los barrios populares ha sido un sub tema de indagación transversal a la exploración de los procesos de resistencia y organización que protagonizan estos jóvenes para reclamar el cese de los atropellos cotidianos, articulados en la acción colectiva denominada Marcha de la Gorra.

Este aspecto se retomará en la sección dedicada al diseño metodológico.

${ }^{4}$ Aplicables a conductas tipificadas como faltas y no delitos, por lo que no alcanzan a ser motivo de aplicación del Código penal.

${ }^{5}$ Esta presión tuvo su punto culminante en las denominadas «razias policiales», por las cuales se llegaron a detener en un fin de semana a más de 300 personas. Fuente: Diario La Voz del Interior. Razias policiales en democracia. Disponible en: http:// www.lavoz.com.ar/opinion/razias-policialesen-democracia. 12/05/2015

${ }^{6}$ En el medio local el carácter racializante del hostigamiento aparece expresado en los criterios de selectividad policial antes mencionados: el color oscuro de la piel. Sin embargo, a diferencia del «stop and frisk», no se aplica a poblaciones afrodescendientes. Es por ello que adquiere sentidos que dialogan con el componente biológico. Para un tratamiento en profundidad, véase Bonvillani (2019).

${ }^{7}$ Debe su nombre al atributo que de manera más significativa identifica a los jóvenes movilizados con su cultura y, a su vez, actúa como criterio de selectividad policial en tanto, desde la vigencia de ciertos imaginarios locales cargados de prejuicios respecto de estos grupos, se considera a la «gorra» un indicador de peligrosidad de quien la porta (Bonvillani, 2015).

8 «Córdoba no Baja» es una campaña organizada por distintas organizaciones sociales en rechazo a la iniciativa del gobierno nacional argentino de bajar la edad de imputabilidad a 15 años junto a la modificación del Régimen Penal Juvenil, endureciendo las medidas punitivas. Junto con la MDG forma parte de las acciones del campo anti-represivo local que se mencionó anteriormente.

${ }^{9}$ Referido a la categoría nativa «bardo» que significa lío, problema.

10 "De los 31 operativos relevados, un total de 23 contaron con corralitos y exposición pública de los detenidos (74\% de los casos)» (Llano en llamas, 2014, p. 3).

${ }^{11}$ Categoría local, insulto vinculado a una práctica sexual. «Cana» : categoría local para «policía».

\section{Bibliografía}

Agamben, G. (2005). Estado de excepción. Buenos Aires, Argentina: Adriana Hidalgo Editora.

Barcala, A., Bonvillani, A., Chaves, M. y Gentile, M. F. (2018). Quién cae dónde. Desigualdades, políticas y construcción socio-estatal de las infancias, adolescencias y juventudes en el escenario argentino actual. En M, 
Vázquez, M. C. Ospina y M. I. Domínguez García (comp.), Juventudes e infancias en el escenario latinoamericano y caribeño actual (pp. 85-108). Buenos Aires, Argentina: CLACSO y Manizales, Colombia: Universidad de Manizales.

Bolatti, V., Frontalini Rekers, R., Job, S., Moyano R., Ortíz de Zárate de Pablo, I., Pérez López S., Truccone Borgogno., S. y Villoslada Gutiérrez, M., (2013). Promoción de derechos humanos en materia de Código de Faltas. Disponible en: https://es.scribd.com/document/129037463/113366386-Relevamiento-y-AnalisisSobre-La-Aplicacion-Del-Codigo-de-Faltas-en-La-Ciudad-de-Cordoba.

Bologna, E., Gómez, P., Morales, S. y Plaza, V. (2017). El derecho a la ciudad en cuestión: segregación residencial y experiencias de circulación de jóvenes en la Ciudad de Córdoba, Argentina. Quid , 16 (7), 125-145.

Bonvillani, A. (2010). Jóvenes cordobeses: una cartografía de su emocionalidad política. Nómadas, 32, 27-45.

(2015). El Código de Faltas de la provincia de Córdoba (Argentina) como dispositivo de poder. La construcción de la seguridad a partir de la equivalencia simbólica «joven pobre=peligroso». Controversias y Concurrencias Latinoamericanas, 7 (11), 81-101.

(2016). Habitar la Marcha: notas etnográficas sobre una experiencia de protesta juvenil. Universitas Psychologica, 14 (5), 1599-1612. Recuperado de http://dx.doi.org/10.11144/Javeriana.upsy14-5.hmne

(2017). Emocionalidad y espacio público: Detenciones arbitrarias de jóvenes de sectores populares de Córdoba (Argentina). Cuaderno Urbano, 23 (23), 107-124.

(2019). 'Negros de alma’. Imaginarios racializados y juvenicidio en la Córdoba de las campanas. Tabula Rasa, 31, 325-346. Doi: 10.25058/20112742.n31.13

(en prensa). Bases racistas de los resortes subjetivos de la dominación: conjeturas respecto de la justificación/ celebración del asesinato de jóvenes de sectores populares de Córdoba (Argentina) a manos de la policía. En S. Cruz Sierra y A. Nateras Domínguez (Coord.), Juventudes en Fronteras: Identidades, cultura y violencia (pp. 67-99). Ciudad de México, México: Colegio de la Frontera Norte.

Butler, P. (2014). Stop and Frisk and Torture-Lite: Police Terror of Minority Communities. Ohio State Journal of Criminal Law, 12, 57-69.

Castorina, J., Barreiro, A. y Toscano, A. (2005). Las representaciones sociales y las teorías implícitas: una comparación crítica. Educação \& Realidade, 30 (1), 201-222.

Centro de Estudios legales y sociales (CELS). (2016). Hostigados: violencia y arbitrariedad policial en los barrios populares. Buenos Aires, Argentina: CELS.

Coria, A. y Etchichury, H. (2010). Código de Faltas Córdoba- Comentarios a partir de la respuesta a un pedido de informe legislativo. Recuperado de http://noalaviolenciainstitucionalcba.blogspot.com.ar/2012/10/codigo-defaltascordobacomentarios.html

Di Leo, P. y Camarotti, A. (2013). Quiero escribir mi historia. Vidas de jóvenes en barrios populares. Buenos Aires, Argentina: Biblos.

Foucault, M. (2002). Vigilar y castigar. Nacimiento de la prisión. Buenos Aires, Argentina: Siglo XXI Editores.

Glaser, B. y Strauss, A. (1967). The discovery of grounded theory. Strategies for qualitative research. New York, Estados Unidos: Aldine Publishing Company. 
González Rey, F. (2002). Sujeto y subjetividad. Una aproximación histórico- cultural. Ciudad de México, México: Thomson.

Isla, A. y Míguez, D. (2011). Formations of Violence in Post-Dictatorial Contexts: Logics of Confrontation between the Police and the Young Urban Poor in Contemporary Argentina. International Journal of Conûict and Violence, 5(2), 240-260.

Jasper, J. (2012). Las emociones y los movimientos sociales: veinte años de teoría e investigación. Revista Latinoamericana de Estudios sobre Cuerpos, Emociones y Sociedad, 4 (10), 48 68. Recuperado de: http:// www.relaces.com.ar/index.php/relaces/article/viewArticle/222

Job, S. (2018). Del Estado Policial al Estado Dron. Formas de gobernanza securitaria en tiempos de racionalidad neoliberal. En M. Díaz de Landa (Comp.) Manual de Sociología Jurídica. Tomo II (pp. 1-37). Córdoba, Argentina Universidad Nacional de Córdoba.

Kessler, G. (2009). El sentimiento de inseguridad. Sociología del temor al delito. Buenos Aires, Argentina: Siglo XXI.

Kessler, G. y Dimarco, S. (2013). Jóvenes, policía y estigmatización territorial en la periferia de Buenos Aires. Espacio Abierto, 22 (2), 221-243.

Le Breton, D. (2009). Las pasiones ordinarias. Antropología de las pasiones. Buenos Aires, Argentina: Nueva visión.

Lerchundi, M. y Bonvillani, A. (2018). Narrativas racistas y criterios de selectividad policial. Experiencias de violentación policial de jóvenes de sectores populares (Río Cuarto, Argentina). Encrucijadas, 16, 1-21.

Llano en Llamas, (2014). Informe Criminalización de la pobreza y judicialización de las luchas políticas/sociales en la Provincia de Córdoba. Recuperado de: www.llanocordoba.com.ar. Accedido 25 de febrero 2016.

Medan, M. (2017). Relaciones conflictivas entre jóvenes en situación de pobreza y policía: su abordaje en programas sociales. Última Década, 47, 83-117. Recuperado de: https://ultimadecada.uchile.cl/index.php/UD/ article/view/48531/51084

Nussbaum, M. (2014). Emociones políticas. ¿Por qué el amor es importante para la justicia? Bogotá, Colombia: Paidos.

Pita, M. V. (2019). Hostigamiento policial o de las formas de la violencia en barrios populares de la Ciudad de Buenos Aires. Relato de una investigación. Desacatos, 60, 78-93.

Rodríguez Alzueta, E. (2017). La policía y la «nada». Perspectivas, 3, 78-88.

Suárez, A. y Bouilly, M. (2012). Acerca de lo policial. Selectividad y violencia. En A. Daroqui, L. López, R. Cipriano García, (Coord.), Sujeto de castigos. Hacia una sociología de la penalidad juvenil (pp.107-133). Buenos Aires, Argentina: Homo Sapiens.

Tufró, M. (2019). Detenciones, demoras e interceptaciones en las dinámicas de hostigamiento policial. Cuestiones Criminales, 3, 118-139.

Valenzuela Arce, J. (2019). Trazos de sangre y fuego: Bio-Necropolítica y juvenicidio en América Latina. Berlín, Alemania: Calas.

Valenzuela Arce, J. (2015) (Coord.). Juvenicidio. Ayotzinapa y las vidas precarias en América Latina y España. Distrito Federal, México: El Colegio de la Frontera Norte, ITESO, NED Ediciones. 
Valles, M. (2007). Entrevistas cualitativas. Madrid, España: Centro de Investigaciones Sociológicas.

Young, J. (2007). El Vértigo de la Modernidad Tardía. Un análisis del papel de la suerte en la atribución de responsabilidad penal. Buenos Aires, Argentina: Didot.

Zaffaroni, E. (2007). El enemigo en el derecho penal. Buenos Aires, Argentina: Ediar. 